\title{
An unusual case of right upper zone pneumonic patch
}

\section{Suman Kumar Jagaty, Mujeeb Rahman KK, Yera Dhanurdhar, Prasanta Raghab Mohapatra}

All India Institute of Medical Science, Bhubaneswar, India

A 32-year-old male heavy smoker presented to outside hospital with history of cough and shortness of breath for 20 days. There was no past history of tuberculosis, cardiac disease or interstitial lung disease. He was diagnosed as right pneumothorax for which chest tube was placed on the right. Immediately after chest tube placement, his dyspnoea increased and he desaturated for which he was referred to our hospital. On admission, his pulse rate was 102/min, $\mathrm{BP}-110 / 70 \mathrm{~mm} \mathrm{Hg}, \mathrm{SPO}_{2}-98 \%$ with 2 litres of oxygen, respiratory rate $-36 / \mathrm{min}$. On examination, chest crepitations over the right infraclavicular and mammary area were found. Other systemic examinations were normal. His symptom was alleviated after oxygen supplementation. His chest radiograph showed right upper zone opacity (Figure 1A) but preceding chest radiograph left at previous hospital manifested right pneumothorax (Figure 1B). Sputum for AFB samples were sent but report came to be negative, then bronchoscopy was done and bronchoalveolar lavage was taken to rule out tuberculosis. Spirometry confirmed chronic obstructive airway disease which could be the cause of pneumothorax. Then repeated chest radiograph (Figure 1C) was done which showed clearing of opacity, which confirmed the diagnosis of reexpansion pulmonary oedema.

Reexpansion pulmonary oedema (RPE) is a rare and lethal complication with 15 to $20 \%$ mortality [1]. RPE was thought to arise from an increased permeability of damaged pulmonary blood vessels, caused by swift reexpansion of lung tissue [2]. Younger age, longer duration of lung collapse ( $>4$ days), large pneumotho$\operatorname{rax}(>30 \%$ of a single lung), airway obstruction, rate of decompression are the risk factors associated with RPE [3-5].

Large pneumothorax, younger age and history of obstructive airway disease in our case favoured development of RPE. His manifestation was mild and managed symptomatically without a need for mechanical ventilation. However, his age, presentation, post chest tube symptom and chest radiograph, particularly unaccompanied by previous radiograph made us suspect strongly of tuberculosis rather than RPE.
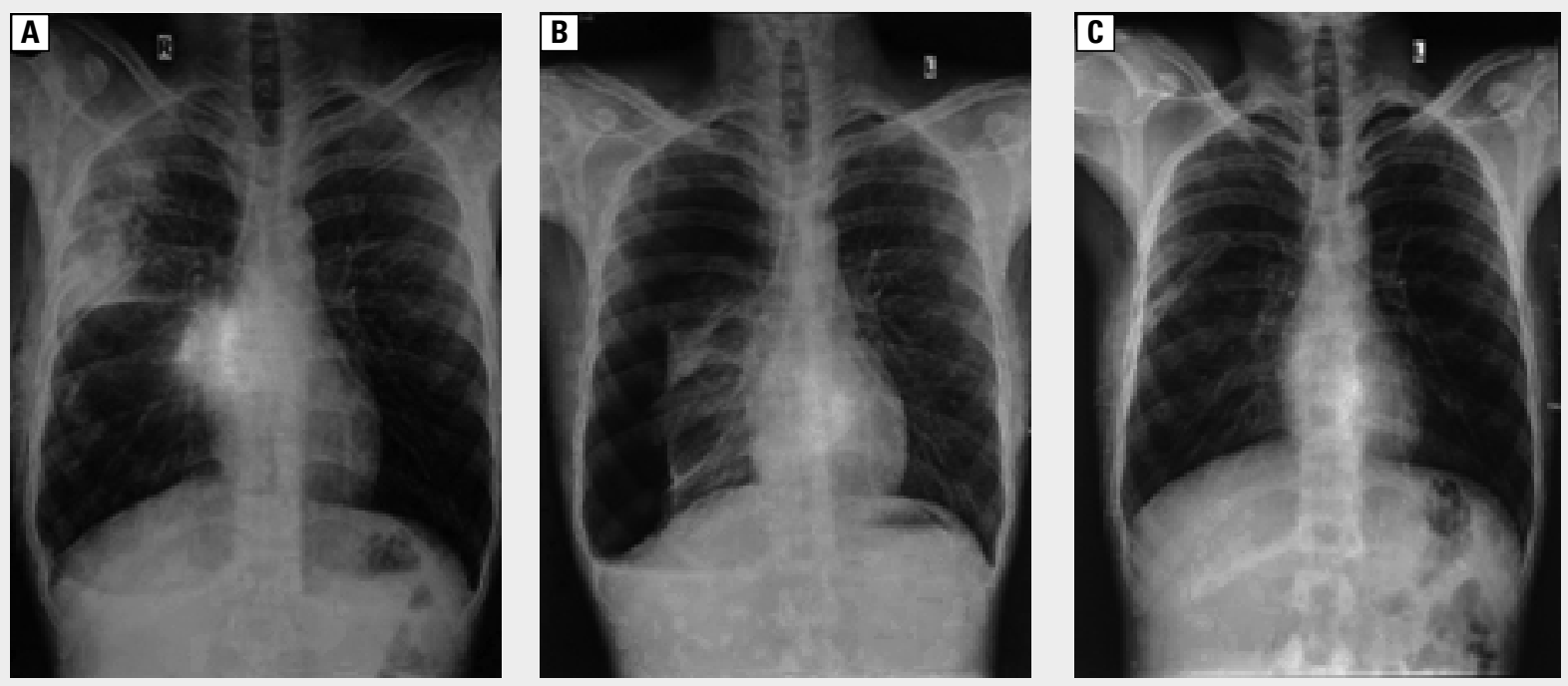

Figure 1. A. On presentation, chest radiograph showing dense, nonhomogenous air-spaced opacity over the right upper zone, horizontal fissure prominence, emphysematous changes with a chest tube in situ; B. Previous hospital chest radiograph showing large right pneumothorax with minimal fluid, collapsed lung noted medially in the right mid and lower zone; $\mathbf{C}$. Repeat chest radiograph showing complete resolution of the radiographic abnormality.

Address for correspondence: Suman Kumar Jagaty, All India Institute of Medical Science, Bhubaneswar, India; e-mail: suman.jagaty@gmail.com DOI: 10.5603/ARM.2020.0092

Received: 05.08.2019

Copyright (C) 2020 PTChP

ISSN 2451-4934

Conflict of interest: none declared 
In India where tuberculosis is endemic, it remains the initial suspicion in case of the patient with three weeks history of cough and right upper zone opacity on chest radiograph. However, reexpansion pulmonary oedema should be kept in first differential diagnosis, particularly in the patient with immediate history of chest tube drainage and thoracocentesis.

\section{References:}

1. Sherman SC. Reexpansion pulmonary edema: a case report and review of the current literature. J Emerg Med. 2003; 24(1): 23-27, doi: 10.1016/s0736-4679(02)00663-7, indexed in Pubmed: 12554036.

2. Sohara Y. Reexpansion pulmonary edema. Ann Thorac Cardiovasc Surg. 2008; 14(4): 205-209, indexed in Pubmed: 18818568.

3. Cha KC, Kim H, Ji HoJ, et al. The frequency of reexpansion pulmonary edema after trocar and hemostat assisted thoracostomy in patients with spontaneous pneumothorax. Yonsei Med J. 2013; 54(1): 166-171, doi: 10.3349/ymj.2013.54.1.166, indexed in Pubmed: 23225814.

4. Murphy K, Tomlanovich MC. Unilateral pulmonary edema after drainage of a spontaneous pneumothorax: case report and review of the world literature. J Emerg Med. 1983; 1(1): 29-36, doi: 10.1016/0736-4679(83)90006-9, indexed in Pubmed: 6689613.

5. Komatsu T, Shibata S, Seo R, et al. Unilateral re-expansion pulmonary edema following treatment of pneumothorax with exceptionally massive sputum production, followed by circulatory collapse. Can Respir J. 2010; 17(2): 53-55, doi: 10.1155/2010/259195, indexed in Pubmed: 20422058. 